NASA Contractor Report 3444

\title{
Modification in Drag of Turbulent Boundary Layers Resulting From Manipulation of Large-Scale Structures
}

T. C. Corke, Y. Guezennec, and H. M. Nagib

GRANT NSG-1591

JULY 1981

LQAF COPY: RCTURfI T:

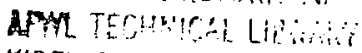

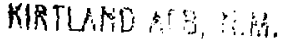


NASA Contractor Report 3444

\section{Modification in Drag of Turbulent Boundary Layers Resulting From Manipulation of Large-Scale Structures}

T. C. Corke, Y. Guezennec, and H. M. Nagib

Illinois Institute of Technology

Chicago, Illinois

Prepared for

Langley Research Center

under Grant NSG-1591

\section{N/Sก}

National Aeronautics

and Space Administration

Scientific and Technical

Information Branch

1981 


\section{SUMMARY}

The effects of placing a parallel-plate "turbulence manipulator" in a boundary layer were documented both through flow visualization, using a "smoke-wire", and hot-wire measurements. The boundary-layer manipulator was designed to manage the large-scale structures of turbulence in a way that may lead to a reduction in the surface drag. First, the outcome of the visualization study is presented to highlight the differences in the turbulent structure of the boundary layer with and without the introduction of the manipulator. Secondly, hot-wire data are summarized to demonstrate differences in various flow properties such as, mean velocity and turbulence intensity profiles, displacement, momentum and energy thicknesses, as well as various ratios of these, and the local friction coefficient along the plate. The parallel-plate manipulator used in this study was found very effective in inhibiting the intermittent large-scale structure of the turbulent boundary layer. This effect persists for at least 70 boundary-layer thicknesses downstream of the manipulator. With the removal of the large scale, there was an observed reduction in the streamwise turbulence intensity levels near the wall. The downstream distribution of the skin friction coefficient, determined from the streamwise change in fluid momentum, was also altered by the introduction of the manipulator. In particular. it decayed at a greater rate than for the non-manipulated boundary layer, although up to the maximum attainable streamwise distance in the wind tunnel, no net decrease in $\mathrm{C}_{f}$ was achieved. 


\section{INTRODUCTION}

The use of screens, grids and honeycombs for "managing" turbulence has been an ongoing area of interest at IIT for sometime. The application of such devices for controlling free-stream turbulence in wind tunnel is best summarized in the publications by Loehrke and Nagib 1,2 . Through careful scaling of mesh sizes and indepth appreciation of the various suppression, and generation mechanisms that control the turbulent flow, these techniques have been quite successful in this application.

Recently, a growing energy conciousness has generated interest in developing techniques for reducing viscous drag on aerodynamic bodies. Recent work, conducted at Langley Research Center by $D$. M. Bushnell ${ }^{3}$, best summarizes the efforts done in this area. In a majority of cases, this implies removing or altering the turbulent boundary layers. Several concepts of flow manipulators which have retained the attention of recent investigations are oscillatory longitudinal curvature, small longitudinal striations and large eddy breakup devices. It is the latter of these three alternatives which is of interest to us and which lends itself as a natural extension to turbulence management techniques. To be most effective, however, it is essential that these "turbulence manipulators" be tailored to the particular mechanisms governing the flowfield of interest. This warrants a review of the current experimental information on wall-bounded turbulent shear flows.

In the last decade, the research on turbulent boundary layers has transformed the picture given by earlier long-time averaged statistics. Once perceived as quasi-steady turbulent eddies transported by a mean shear, such flows appear, as a result of short-time conditioned measurements, to be highly unsteady. coherent motions of strongly interacting scales. The recent interpretations of such conditioned statistics ${ }^{4}, 5$ and visual studies ${ }^{6}, 7$ in turbulent boundary layers suggest that a strong cause-and-effect interaction exists between the large outer scales and the small scales near the wall. In particular. the wall region is observed to be dominated by a sequence of events known as "bursting". These "bursts" are characterized by the ejection of low-speed fluid from the wall and are found ${ }^{B}$ to produce the majority of the turbulence energy and mixing near the wall. Recent measurements 47 indicate that these ejections are triggered by the sharp acceleration and inflexional profile associated with the sweep of high-speed fluid from the outer flowfield. This phenomenon is thought to be of fundamental importance for sustaining the growth of a turbulent boundary layer, i.e., an important mechanism to surface drag in turbulent boundary layers.

In light of these results, one can speculate that if the intermittent outer structure in a turbulent boundary layer is altered or removed, the "bursting" of fluid from the wall may be interrupted or impeded. This reduced activity would also inhibit the interaction of high-speed and low-speed fluid near 
the wall, thereby, leading to frequent reduction in the instantaneous local shear stress at the surface. There are also obvious implications regarding the generation of "new" turbulence. The results of this paper represent our first attempt at "managing" the large-scale intermittent structure as a means for controlling some of the dominant mechanisms in a turbulent boundary layer.

In this initial study we chose to use a two-dimensional honeycomb-like arrangement 1,2 made up of four stacked parallel plates. This "manipulator" was selected because it represented a minimum obstruction to the flow, when compared to screens or perforated plates, and because it gave us the greatest amount of design freedom for matching the device to the scales of interest. Based on our previous experience ${ }^{1,2}$ in turbulence management the parallel plate arrangement was deemed more appropriate than a full honeycomb, because it provided the full suppression and generation mechanisms without the added drag of the vertical members. The objectives for this preliminary study were then to demonstrate that such a device was capable of removing the large-scale intermittent structures in a turbulent boundary layer and to document the characteristics of the "manipulated" flow. To aid as a bench mark, a comparable "natural" boundary layer was generated and documented. The visual differences were recorded through photographs obtained using the smoke-wire technique. In addition, hot-wire measurements were made to compare the various mean and statistical aspects of the flow. Special emphasis would be placed here on the magnitudes of the local friction coefficient and its streamwise distribution. 


\section{SYMBOLS}

$c_{f} \quad$ skin-friction coefficient $\equiv \tau_{w} / 1 / 2 \rho U_{\infty}^{2}$

G equilibrium shape factor $\equiv \int_{0}^{\delta}\left(\frac{U_{\infty}-\bar{U}}{u_{\tau}}\right)^{2} a\left(\frac{y}{\Delta}\right)$

H shape factor $\equiv \delta_{1} / \delta_{2}$

$\ell$ chord dimension of parallel plate manipulator

$\operatorname{Re}_{\mathrm{L}}$ Reynolds number $\equiv U_{\infty} L / U$, where $L=x$ or $\delta_{2}$

$\mathrm{U}$ streamwise velocity component $\equiv \overline{\mathrm{U}}+\mathrm{u}$

$u$ fluctuating component of streamwise velocity, $U$

$\bar{U} \quad$ time-averaged mean of streamwise velocity component

$\mathrm{U}_{\infty} \quad$ time-averaged free-stream velocity

$u^{*} \quad$ rms value of fluctuating velocity, $u$

$u^{+} \bar{U} / u_{\tau}$

${ }^{u_{\tau}}$ wall shear velocity $\equiv \tau_{\mathrm{W}} / \rho$

$\mathbf{x}$ Cartesian coordinate in streamwise direction; origin at leading edge of plate

$x_{0}$ downstream distance between leading edge of plate and turbulence manipulator

y Cartesian coordinate taken normal to flat plate; origin at plate surface

$y^{+} \quad y u_{\tau} / v$

z Cartesian coordinate taken parallel to flat plate; origin along plate centerline

$\beta \quad$ equilibrium parameter $\equiv \frac{\delta_{1}}{\tau_{W}} \frac{d p}{d x}$

$\Delta \quad$ Clauser thickness $\int_{0}^{\delta} \frac{U_{\infty}-\bar{U}}{u_{\tau}} d y$ 


$$
\begin{aligned}
& \delta \quad \text { boundary-layer thickness } \equiv \mathrm{y} \text { value where } \overline{\mathrm{U}} \text { equals } 0.995 \mathrm{U}_{\infty} \\
& \delta_{1} \text { displacement thickness } \equiv \int_{0}^{\delta} \frac{\mathrm{U}_{\infty}-\bar{U}}{\mathrm{U}_{\infty}} d \mathrm{y} \\
& \delta_{2} \text { momentum thickness } \equiv \int_{0}^{\delta} \overline{\mathrm{U}}_{\infty}\left(1-\overline{\mathrm{U}}_{\infty}\right) \mathrm{dy} \\
& \left.\delta_{3} \text { energy thickness } \equiv \int_{0}^{\delta} \overline{\overline{\mathrm{U}}}\left(1-[\overline{\overline{\mathrm{U}}}]_{\infty}\right]^{2}\right) \mathrm{dy}
\end{aligned}
$$

5 distance downstream of manipulator where measurements were taken

$\delta \quad$ fluid density

$\tau^{\tau} \quad$ wall shear stress

$u \quad$ kinematic viscosity

5 
The visualization experiments and hot-wire measurements were performed in the high-speed test section of the IIT Environmental wind Tunnel. The turbulent boundary layers used in the study were generated on a $3.3 \mathrm{~m}$ long flat plate suspended at the mid-height of the $0.6 \times 0.9 \mathrm{~m}$ test section of the wind tunnel. The free-stream velocities in this experiment ranged from 1.5 to $10 \mathrm{~m} / \mathrm{s}$. For the naturally developing shear layers on the plate, this resulted in Reynolds numbers based on development length. $\operatorname{Re}_{x}$, and momentum thickness, $\operatorname{Re}_{2}$, which range from $3 \times 10^{5}$ to $2 \times 10^{6}$ and from 900 to 4100 , respectively. In addition to these, for the same range of velocities, artificially tripped boundary layers were investiqated for comparison. The results presented in this paper are for a fixed free-stream velocity of approximately 7.5 $\mathrm{m} / \mathrm{s}$. $\left(\operatorname{Re} \delta_{2} \simeq 3500\right)$, although the manipulator was observed to perform equally well in the range of velocities listed. The flat-plate and parallel-plate "turbulence manipulator" are schematically shown in Figure 1. Also shown are the Cartesian coordinates for the experiment with their origins at the leading edge of the plate, the surface of the plate and the transverse centerline of the plate for the $x, y$ and $z$

directions, respectively. In addition to these, such laboratory coordinates as $x_{0}$, which is the streamwise distance between the manipulator and the leading edge of the boundary-layer plate, and $\xi$, which denotes the downstream distance of a measurement station from the trailing edge of the manipulator, are presented in Figure 1. For the case of the tripped boundary layer, a 3.2 $\mathrm{mm}$ thick piece of angle-iron with legs of 2.5 and $1.3 \mathrm{~cm}$ was placed $15 \mathrm{~cm}$ from the leading edge. The angle-iron spanned the flat plate and was oriented so that the longer leg pointed upstream.

The boundary-layer plate was constructed from two separate plates. The upstream part was made from $1.6 \mathrm{~cm}$ thick aluminum onto which was machined a downward sloping, sharp leading edge. To facilitate viewing of the visualized flowfield, the downstream plate was made from $1.3 \mathrm{~cm}$ thick clear plexiglass. This plate was fastened along its perimeter to a metal frame which maintained a flat surface. The two plates were joined flush at the streamwise location of $1.6 \mathrm{~m}$.

Turbulence manipulator

The "turbulence manipulator" utilized in this study consisted of four plates, vertically stacked in a parallel arrangement and spanning the tunnel test section. All of the plates were $0.7 \mathrm{~mm}$ thick and had a streamwise chord, $\ell$, of 75 $\mathrm{mm}$. The manipulator was designed to remove all of the dominant scales in the turbulent boundary layer. Therefore, the spacing 
between plates becomes successively closer at lower elevations (z) in the boundary layer. For this manipulator the plates are located at vertical heights of $7,17,34$ and $64 \mathrm{~mm}$.

For the results presented here, the manipulator was located at the streamwise distance $x_{0}=1.4 \mathrm{~m}$ from the leading edge of the flat plate. At this location, the boundary layer, which developed naturally, was fully turbulent with the manipulator extending to approximately 80 percent of the mean boundary-layer height.

Smoke-Wire Visualization

A flow visualization technique, utilizing a "smoke-wire" for introducing controlled sheets of smoke streaklines, was used to visually record the different aspects of the turbulent structures in the boundary layer with and without the introduction of the flow manipulator. For details on this technique the reader is directed to the paper by Corke et al. ${ }^{9}$, and for its use in a similar application to Nagib et al ${ }^{\text {. }}$

To obtain the photographic records of the flow, the "smoke-wire" was located at the upstream edge of the plexiglass plate and oriented either vertical or horizontal to the plate surface. With the wire oriented vertically, two different views were obtained. When the streaklines were illuminated by a sheet of light oriented in the plane of the generating wire (i.e., perpendicular to the plate), and when viewed from the side, a visual "cut" in the boundary layer, perpendicular to the floor and extending in the streamwise direction was obtained. An end-on view of this "cut" in the boundary layer was obtained by illuminating the streaklines with the light oriented parallel to the plate and viewing the flow from below through the clear plexiglass floor.

With the plane of light and the generating wire oriented parallel to the flat plate, and when viewed from below, a visual "cut" spanwise through the boundary layer and extending in the streamwise direction was obtained. The height in the boundary layer at which each "cut" was visualized, was determined by the elevation of the horizontal "smoke-wire" from the floor. An example of these three views is respectively presented from top to bottom in Figure 2, which will be detailed in the section on Results and Discussion.

Hot-Wire Measurements and Digitial Acquisition

The hot-wire measurements were obtained by digitally acquiring the output voltage of a constant temperature anemometer connected to a single wire probe suspended in the flow. In addition to the anemometer output, the output of a pressure transducer monitoring the free-stream dynamic pressure 
at one station of the test section, a voltage proportional to the temperature in the test section, and two voltages proportional to the vertical and streamwise probe locations were simultaneously digitized. The voltages were sampled at 500 samples/sec and recorded on digital magnetic tape for further processing on a Univac 1108 computer. The data were arranged into records containing 1503 data points for each of a selected number of vertical distances above the surface of the boundary layer plate. This was done for a total of nine streamwise locations along the centerline of the plate.

The data tapes were processed and used to generate a set of digital records made up of mean and rms velocity profiles. Special care was taken in this phase of the processing for calculating the velocities corresponding to the anemometer output. In this case the velocities were determined from a "best fit" fourth-order polynomial calibration curve and fully temperature compensated through the relations determined by Drubka et al. 11

Since one of the main concerns of this work was the computation of the local friction coefficients, we were interested in obtaining an accurate measurement of the friction velocity, u, . Because of a mildly favorable pressure gradient $(B=0.14)$ that existed along the tunnel test section, and because. with the introduction of the manipulator, the velocity profiles contained the decaying wakes of the manipulator plates, the momentum integral equation

$$
\frac{d}{d x}\left(U_{\infty}^{2} \delta_{2}\right)+\delta_{1} U_{\infty} \overline{d U}_{d x}=\frac{\tau_{w}}{\rho}
$$

was chosen to solve for $\tau_{w}$.

The method first consisted of calculating $U_{\infty}(x)$ from each of the velocity profiles. These values were chosen to be the average velocity measured at an elevation where the mean vertical (y) change of $\bar{U}$ was within a specified value. The values of $U_{\infty}(x)$ at each streamwise position were then fitted by a polynomial to obtain $\mathrm{dU}_{\mathrm{o}} / \mathrm{dx}$.

Because of the low confidence levels given to the data points closest to the floor, and because of the inherent difficulties in making measurements in the sublayer of a boundary layer in air ( $y$ at $y^{+}=10$ equals approximately 0.5 $\mathrm{mm})$, the following scheme was used to compute the quantities needed in the solution of the momentum equation. Initially for each velocity profile, the datum point closest to the surface of the flat plate was chosen as an "initial-guess" for $y$ corresponding to $\mathrm{y}^{+}=10$. The velocity profile was subsequently taken to be linear to that height and to pass through the data points at all higher elevations. The profiles were then integrated to obtain $\delta_{1}(x), \delta_{2}(x)$ and $\delta_{3}(x)$. In the process of 
integration, the profiles were smoothed by fitting a parabola through successive groups of three data points. Two data points of each group were overlapping. The integral values of the parabolic profiles taken across the overlapping regions were subsequently averaged and summed to obtain the total integral value for the complete mean profile. For use in the momentum equation, $\delta_{2}(x)$ was $f i t$ by the power-law equation

$$
\delta_{2}(\mathrm{x})=A \mathrm{x}^{\mathrm{n}}
$$

to obtain $\mathrm{d} \delta_{2} / \mathrm{dx}$

The values taken from the "initial-guess" were substituted into the momentum equation to generate a "newn $\tau_{w}(x)$. The new values of were used to compute new values of $y$ at $y^{+}=10$ and the corresponding velocity values at that height taken from the linear velocity distribution.

$$
u^{+}=y^{+}
$$

Using these values the new profiles were again integrated to compute $\delta_{2}(\mathrm{x})$ and $\mathrm{d} \delta_{2} / \mathrm{dx}$ and substituted into the momentum equation to obtain $\tau_{w}(x)$. The solution continues to loop until consecutive $\tau(x)$ values were essentially identical. Convergence typically occurred after four iterations. 
The results presented here consist of the visually observed changes in the large-scale turbulent structure of the boundary layer, and the differences in the mean quantities of the flow caused by the addition of the turbulence manipulator. Although there are undoubtedly also differences in the unsteady aspects of the flow. including turbulence generation and "bursting" near the wall this paper is primarily concerned with the modification of the skin friction when the large scales are altered by the manipulator. The interrelation between the outer structure and the wall structure is currently being studied with the aid of a family of manipulators. The results of that study provides further extension and interpretation of results presented in the following.

Visualization Results

Photographic records of three different views of the naturally developed turbulent boundary layer $\left(\operatorname{Re} \delta_{2}=1800\right)$, at one instant in time, are presented in Figure 2. The streamwise extent of these photographs corresponds to approximately 7 boundary-layer thicknesses. In the top photograph, the large-scale outer structure is clearly visible with the intact streaklines marking the potential flow. Close inspection of this photograph reveals regions of potential high-speed fluid that extend close to the surface of the flat plate. When this sheet of smoke is viewed from below, although not at the same instant in time, the view recorded by the middle photograph is obtained. Observed here is the three-dimensional spreading of the sheet of smoke streaklines that correlates with the large scale turbulence. The quiescent portions observed in this view of the sheet of streaklines correspond to regions of high intermittency. A spanwise view of the boundary layer. obtained with a generating wire parallel to the surface, is displayed in the lower photograph of the figure. This view demonstrates the spatial intermittency that exists at this instant in time in the boundary layer at $y / \delta=0.8$. Such "islands" of potential flow result from the large-scale corrugations in the turbulent-nonturbulent interface.

The photographs of Figure 2 were obtained in a naturally developed boundary layer. The effect of placing the parallel plate manipulator in the boundary layer can be observed by contrasting the photographs of that figure with those of Figure 3. The most notable difference is a lack of large-scale turbulence and a redistribution of the fine scales.

The comparison made here is typical of the records obtained in turbulent boundary layers at the same and different Reynolds numbers. The effects of the manipulator have been observed, in this study, to persist for at least 25 boundary-layer thicknesses downstream of the manipulator, the maximum streamwise location attainable in the present test-section 
arrangement. Measurements using a thinner boundary layer and a two-plate manipulator have increased the observed streamwise extent without a reoccurrence of the large-scale turbulence by a factor of 3. Quantitative hot-wire data are presented in the following to demonstrate the differences in the mean characteristics of the boundary layer resulting from the addition of the manipulator.

Hot-Wire Results

A comparison of the mean velocity and turbulence intensity profiles, at one streamwise location, in the natural and manipulated boundary layers is shown in Figure 4. A larger momentum defect is evident at this station for the boundary layer with the manipulator. This is a result of the additional drag generated by the device. The wake of the uppermost plate of the manipulator is evident in this profile and in the comparable turbulence intensity distribution in the graph below. Focusing attention near the surface of the plate reveals a reduction in the turbulence intensity for the manipulated boundary layer. This result is further illustrated in Figure 5 in which the lowest portion (below $y^{+} \approx 100$ ) of the turbulence intensity profiles for the two cases is displayed, for different streamwise stations. For comparable streamwise distances, we observe approximately a 10-percent reduction in the value of $\mathrm{u}^{\prime} / \mathrm{U}_{\infty}$ with the addition of the manipulator. This may indicate a decrease in the turbulence generation or "bursting" process in the wall layer.

The log-linear representation of the mean velocity profiles for the natural, tripped and manipulated boundary layers is shown in the top portion of Figure 6, for one of the streamwise stations. Also shown is the "law of the wall" profile using the constants given by Coles. ${ }^{2}$ In the lower graphs of the same figure are the log-linear profiles for the manipulated boundary layer at increasing downstream distances. It is evident here that the shift in the curves reflects the larger friction velocities that exist downstream of the manipulator. It is interesting to note that at the furthest streamwise station there is a boundary layer which exhibits the "classical" mean velocity profile but totally lacks any large intermittent eddies. This result indicates that such time-mean measurements are not sufficient to completely catagorize the state of a turbulent shear flow. Rather, information about the scales is also required.

The streamwise variation of the momentum thickness, $\delta_{2}(x)$, is presented in Figure 7 for the three boundary layers. This figure depicts the larger momentum deficit produced by the manipulator. In terms of the friction drag, however, the local slope is the determining factor. This requires that for a net reduction in the drag, the streamwise distribution of the 
momentum thickness for the natural and manipulated boundary layers must cross.

Although a larger momentum thickness is observed for the manipulated boundary layer, the streamwise distribution of the shape factor. shown on the top portion of Figure 8 , indicates a disproportionate increase in the displacement thickness. The streamwise distribution of the equilibrium shape factor, shown on the bottom portion of this figure, reveals no strong trends. The values of $G(x)$, however, fall about a mean of 6.5 which has been commonly observed for a turbulent boundary layer under a comparable pressure gradient.

The ratio of the energy thickness to the momentum thickness is plotted versus the shape factor in Figure 9. In addition to the disproportionate growth of $\delta_{1}$ compared to $\delta_{2}$ in the manipulated boundary layer, this figure reveals that the ratio, $\delta_{2} / \delta_{3}$, is large when compared to the other two cases. When plotted in the form of Figure 9 however, the trends compare well with the data of Rotta, and wieghardt and Tillman which was reproduced from schlichting. 5 The differences in the magnitudes of the values is approximately one percent.

The distribution of the local skin-friction coefficient, computed at each streamwise station, is shown in Figure 10, for the three boundary layer cases. A gradual decrease in the local coefficient is revealed for the natural and tripped boundary layers. The slight upswing at the tail of the curves is a result of blockage effects at the end of the test section. In case of the boundary layer controlled by the manipulator. a large local coefficient is measured directly downstream of the device. However, because of the more rapid decrease in this quantity with downstream distance. the $C_{f}$ value at the last measuring station is approximately the same as that for the regular boundary layer. If the distribution maintains this slope. a net drag reduction may be realized with sufficient downstream distance. 


\section{CONCLUSIONS}

A parallel-plate manipulator, placed in a turbulent boundary layer over a range of Reynolds numbers based on momentum thickness from 900 to 4100 , was found to be effective in removing the intermittent large-scale outer structures. Recent smoke-wire visualization records in a thinner boundary layer have revealed that the controlling aspects of the manipulator persist for at least 800 momentum thicknesses (approximately 70 manipulator heights) downstream of the device. Hot-wire surveys of the boundary-layer profiles reveal that the streamwise distribution of the local skin-friction coefficient is altered by the addition of the manipulator. In particular. it exhibits a higher decay rate, beginning at a $C_{f}$ level approximately 30 percent above that for the boundary layer alone (immediately downstream of the manipulator) and crossing that distribution approximately 250 momentum thicknesses downstream, the maximum attainable streamwise measurement station.

Near the wall $\left(y^{+}<100\right)$ the streamwise turbulence intensity was reduced by approximately 10 percent with the addition of the manipulator. This may reflect the lack of high-speed potential fluid being entrained towards the wall or it may be interpreted as a reduction in the "bursting" activity in this region. Since there is speculation that these events are related through a feedback mechanism, 4,7 the recorded differences may be a combination of both effects. The fact that one link in this chain can be removed, by the use of the manipulator. may provide some answers to the fundamental questions related to this process.

It is important to emphasize that the data presented here are the results of a preliminary investigation on the control of the characteristics of a turbulent boundary layer in order to reduce the friction drag. Further measurements will attempt to reaffirm these results while examining greater downstream distances from the manipulator. The parallel-plate manipulator. described here, was the only one utilized in these preliminary experiments. Through visualization records, documentation has been made of the effects of a family of such devices that require a fewer numbers of plates to control the large scales to the same degree as that exhibited with the four-plate manipulator. These devices will be used to document changes in the unsteady aspects of the turbulent boundary layer. It is hoped that with this approach based on flow management ideas, insight can be provided into the link between turbulence production and coherent large-scale structures in wall-bounded turbulent shear flows. 
The calculation of the momentum equation used to determine the wall-friction coefficients presented in this study was the result of a complex computational scheme which required the fitting of the data to numerical equations in order to form the terms in the momentum balance. The value of the local friction coefficient, $C_{f}$, is very sensitive to the variation of the momentum thickness, and more precisely, proportional to the downstream gradient of the momentum thickness in the absence of pressure forces. The power-law equation used to fit these distributions was forcing the behavior of the data by requiring the first and second derivatives of $\delta 2(x)$ to decrease in a prescribed fashion with increasing downstream distance. $x$. This was especially restrictive in the case of the manipulated boundary layer with its additional momentum losses resulting from the device.

This limitation has been resolved by using a spline function with weighting and damping to fit the local values of the free-stream velocity, momentum thickness, and their derivatives. This procedure does not require any pre-supposed form for the numerical fit. In this form the program has been tested with our data as well as the data of other investigators. The results give excellent agreement between the values of the friction coefficient obtained by our momentum balance and those reported in the literature for regular boundary layers. These results as well as the results of drag measurements in another "manipulated" boundary layer having lower device drag will appear in a future NASA report. 


\section{REFERENCES}

1. Loehrke, R. I.; and Nagib, H. M.: "Experiments on Management of Free stream Turbulence," AGARD Report No. 598 , 1972 ; also available from NTIS as AD-749-891

2. Loehrke, R. I.; and Nagib, H. M.: "Control of Free stream Turbulence by Means of Honeycombs: A Balance Between Suppression and Generation," ASME Paper 76-Fe-2; J. Fluids Eng., Trans. ASME, Vol. 98, No. 3, 1976.

3. Bushnell, D. M.: Recent Turbulent Drag Reduction At Langley Research Center, "NASA Technical Memorandum 78688, March 1978.

4. Chen, C. P.; and Blackwelder, R. F.: "Large-scale Motion in a Turbulent Boundary Layer," J. Fluid Mech., Vol. 89, Part 1. pp $1-31.1978$.

5. Blackwelder, R. F.; and Eckelmann, H.: "Streamwise Vortices Associated with the Bursting Phenomenon," J. Fluid Mech., Vol. 94, Part 3, pp $577-594$, 1979.

6. Kim. H. T.; Kline, S. J.; and Reynolds, W. C.: "The Production of Turbulence Near a Smooth wall in a Turbulent Boundary Layer," J. Fluid Mech., Vol. 50, Part 1, pp $133-160$, 1971.

7. Praturi, A. K.; and Brodkey, R. S.: "A stereoscopic Visual Study of Coherent Structures in Turbulent Shear Flow, "J. Fluid Mech., Vol. 89, Part 2. pp 251-272, 1978.

8. Lee. S. S.; and Willmarth, W. W.: "Measurements of the Structure of the Reynolds Stress in a Boundary Layer," J. FIuid Mech., Vol. 60, Part 3, pp 481 - 511, 1973.

9. Corke, T.; Koga, D.; Drubka. R.; and Nagib, H.: "A New Technique for Introducing Controlled Sheets of Smoke streaklines in wind Tunnels," Proceedings of International Congress on Instrumentation in Aerospace simulation Facilities, IEEE Publication $77 \mathrm{Chl251-8,} \mathrm{AES,} \mathrm{1977,} \mathrm{p} 74$.

10. Nagib, H. M.; Guezennec, Y.; and Corke, T. C.:

"Application of a Smoke-wire Visualization Technique to Turbulent Boundary Layers," Workshop on Coherent Structures of Turbulent Boundary Layers, Lehigh University, May, 1978.

11. Drubka. R. E.; Tan-atichat, J.: and Nagib, H. M.:

"Analysis of Temperature Compensating Circuits for Hot-Wires and Hot-Films," DISA Information, No. 22, December, 1977, pp $5-14$.

12. Coles, D.: "Young Person's Guide to Data," Proceedings of Computation of Turbulent Boundary Layers - 1968, Vol. 2 .

Stanford University, August, 1968, pp $1-45$. 

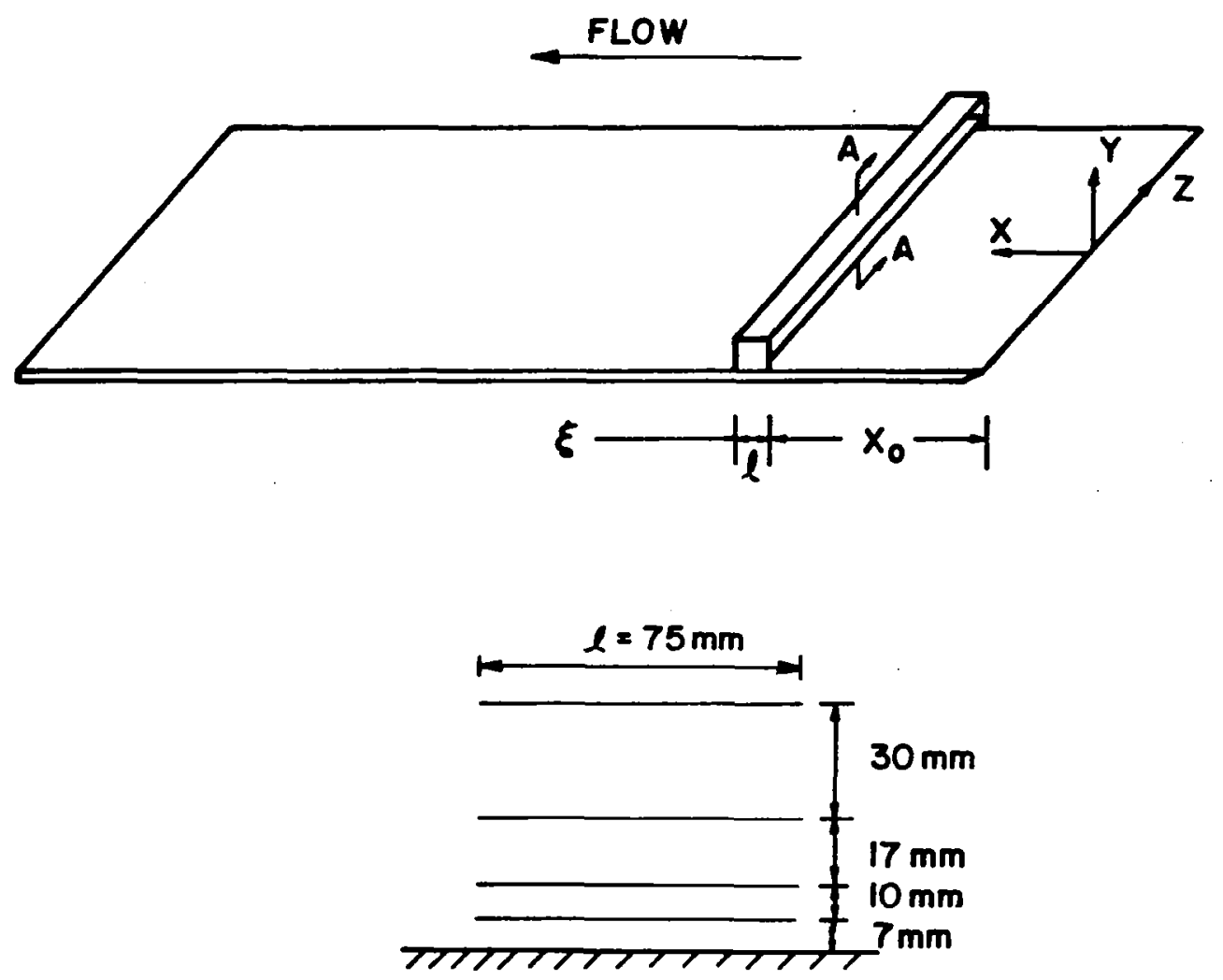

\section{SECTION A-A}

Figure 1. Schematic representation of four plate turbulence manipulator and its arrangement on boundary-layer plate, with laboratory coordinates. 


\section{ELOW}

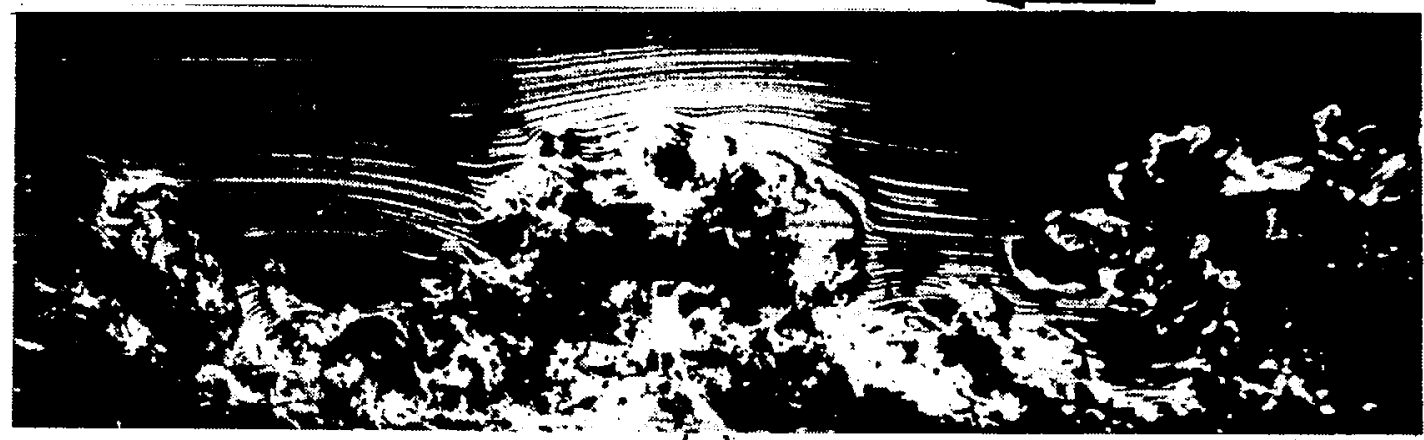

(a)

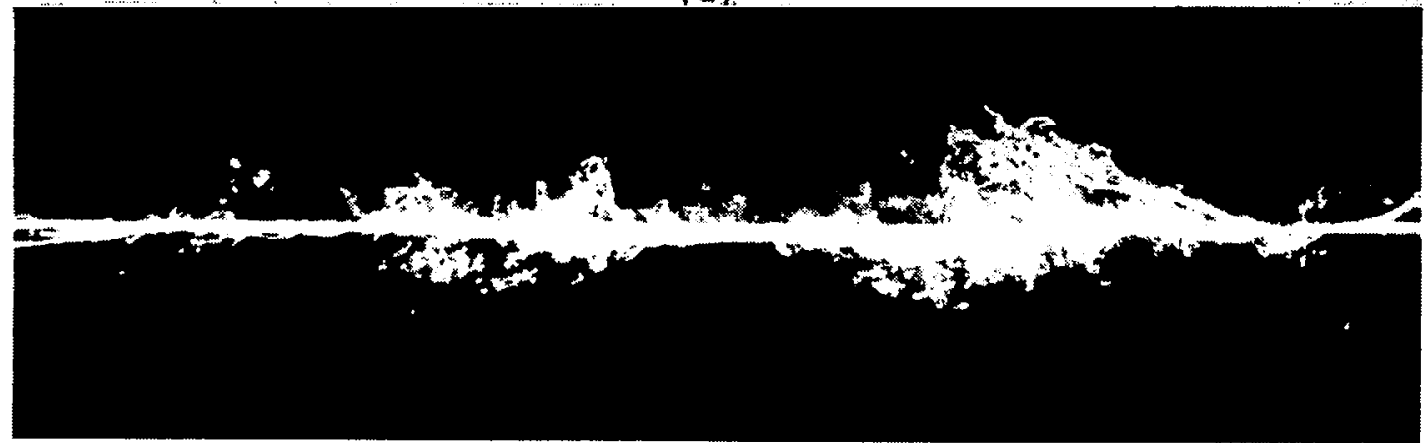

\section{(b)}

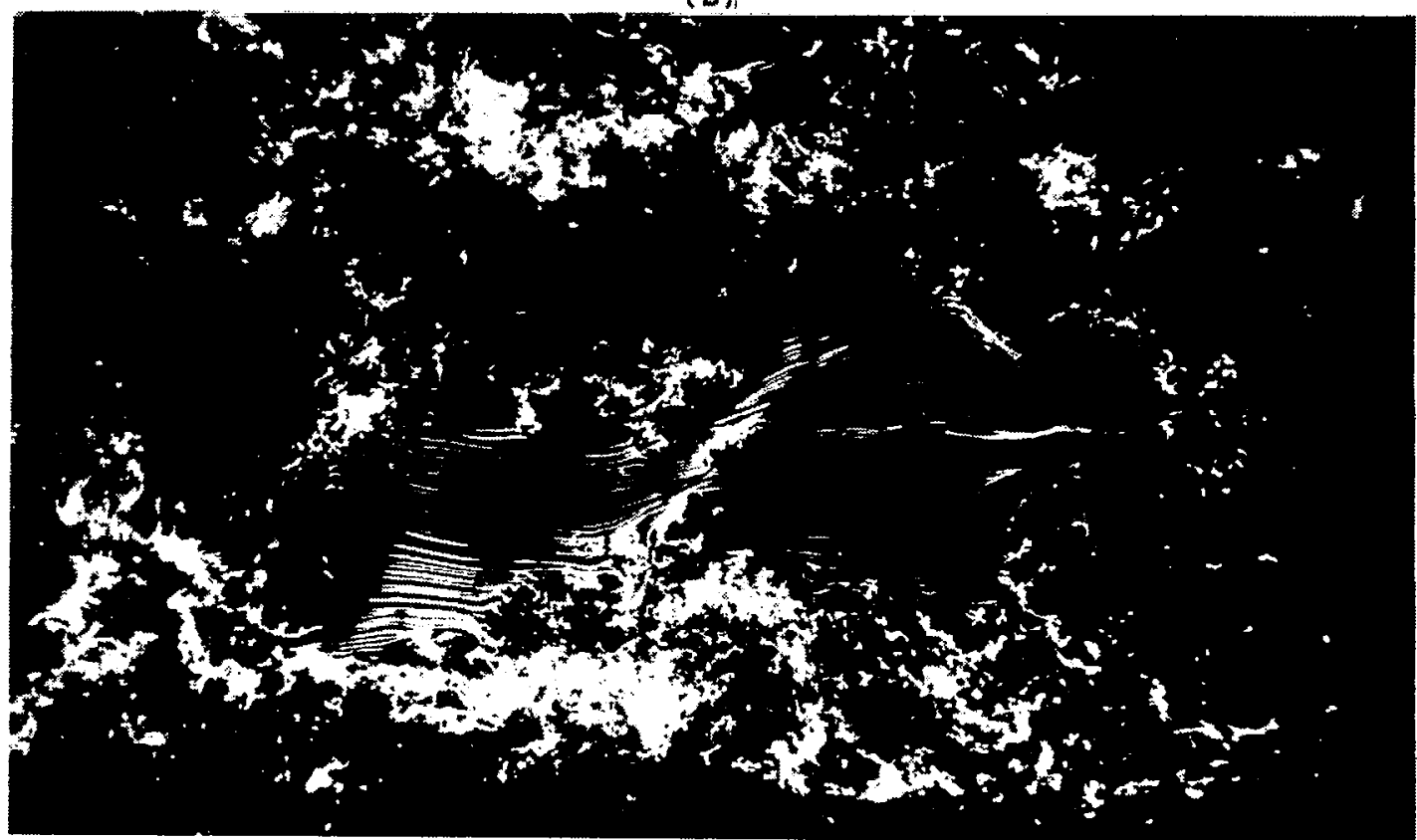

Figure 2. Visualization of a turbulent boundary layer, developed naturally on a horizontal plate, as viewed from side (a) and bottom (b) for a vertically oriented smoke wire, and from bottom (c) for a horizontally oriented wire. 


\section{ELOW}

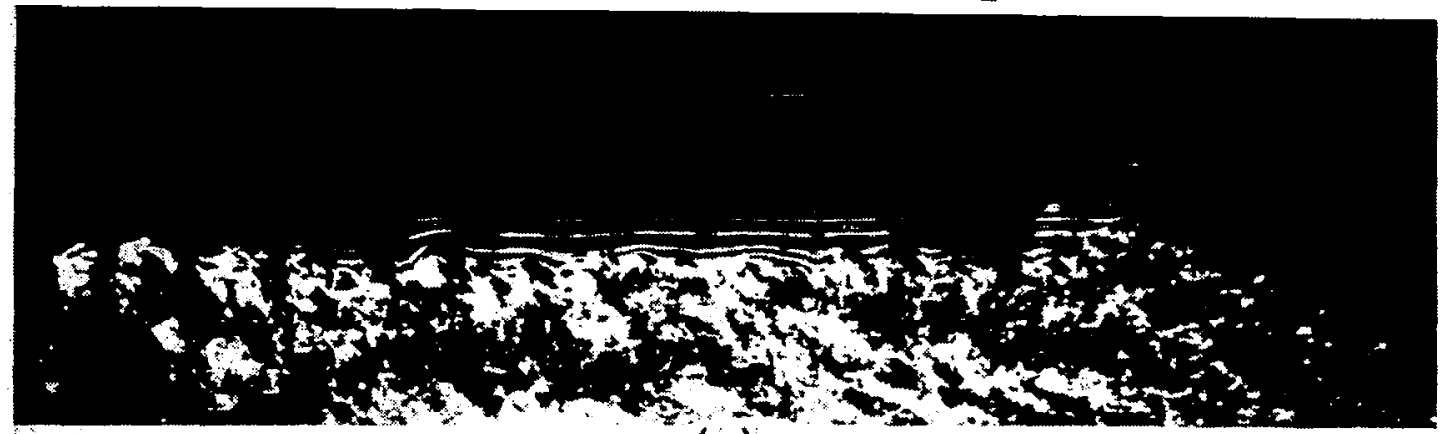

(a)

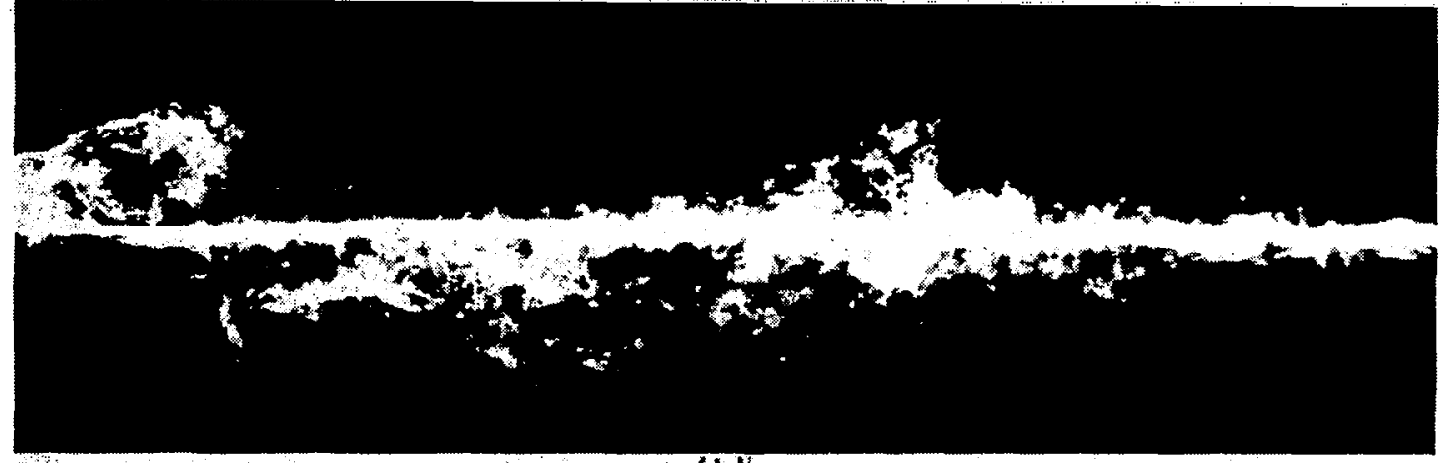

(b)

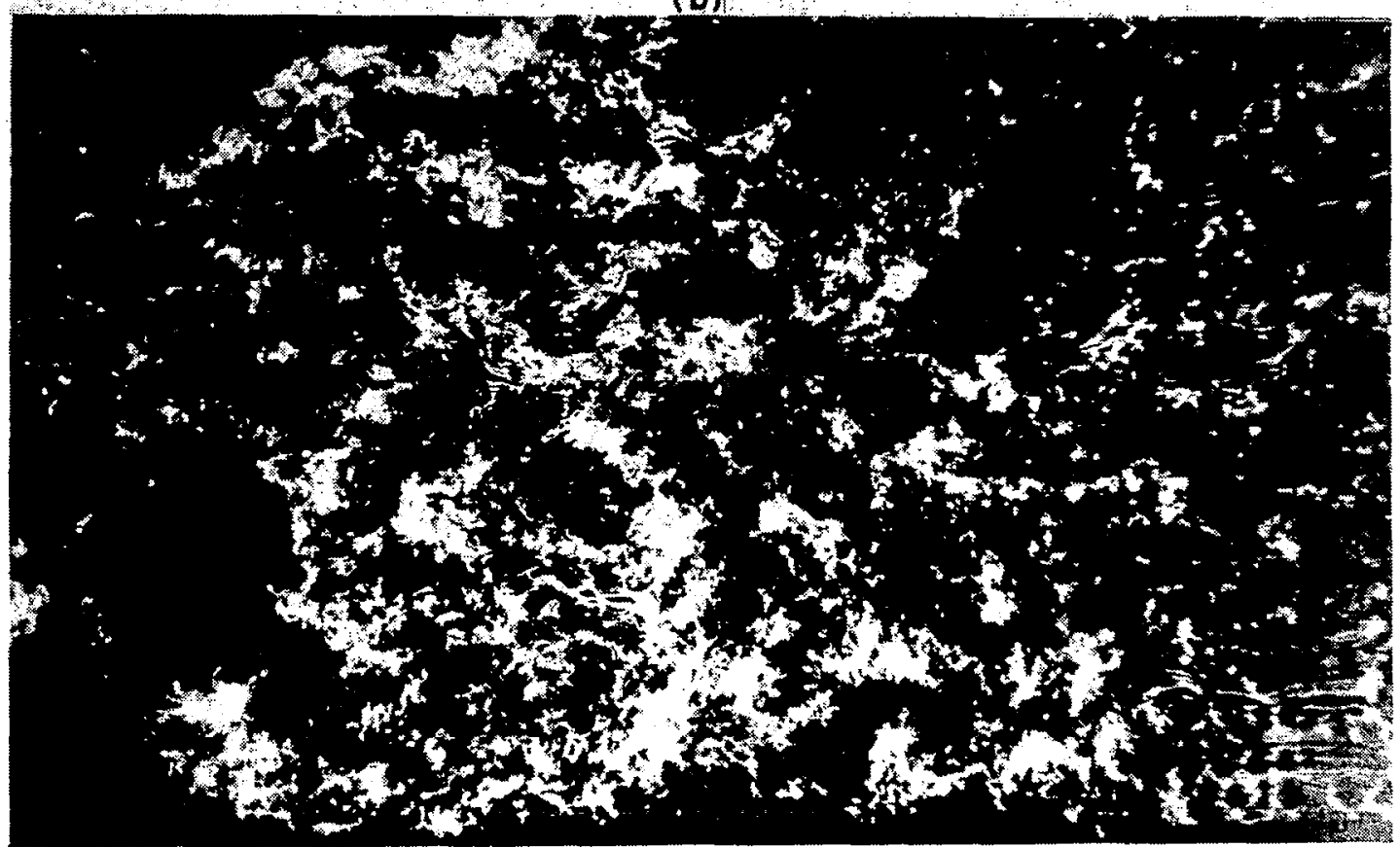

Figure 3. Visualization of $(c)$ turbulent boundary layer, on horizontal plate downstream of parallelplate boundary layer manipulator 1 , as viewed from side (a) and bottom (b) for a vertically oriented smoke wire. 

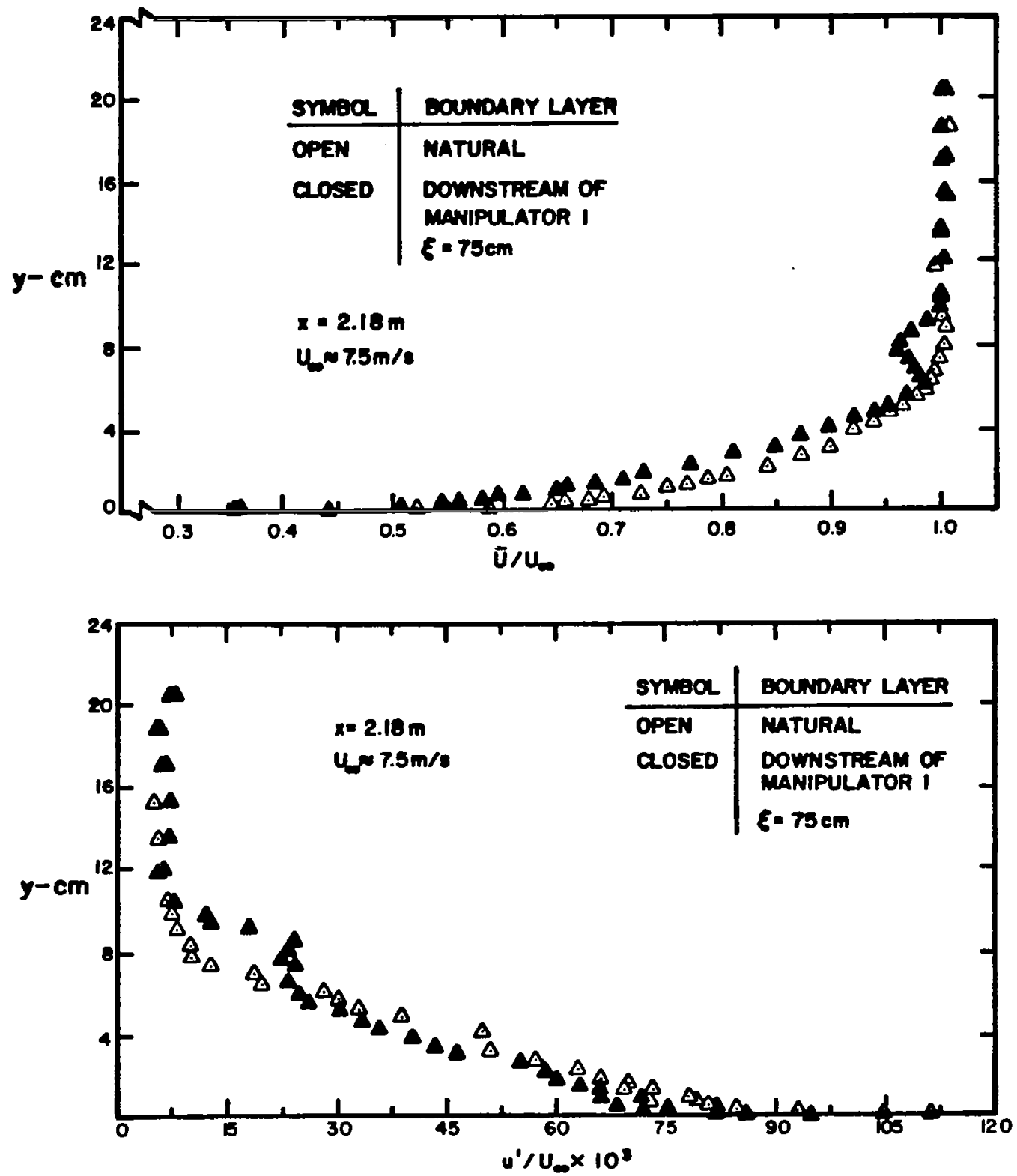

Figure 4. Mean velocity and turbulence intensity profiles for boundary layer with and without the addition of parallel-plate manipulator. 


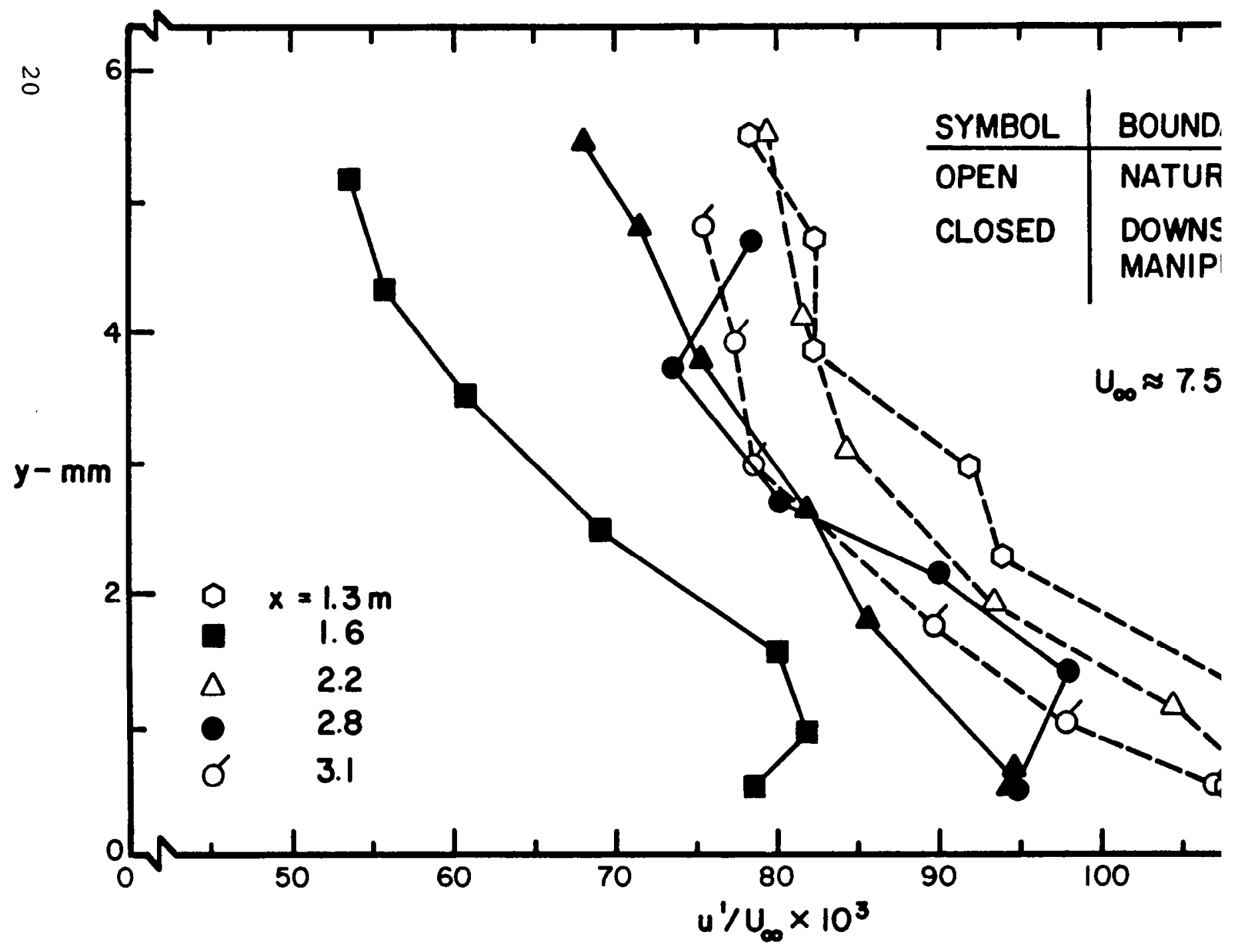

Figure 5. Magnified view of streamwise turbulence intens profile below $\mathrm{y}^{+}=100$ for boundary layer with without the addition of turbulence manipulator 

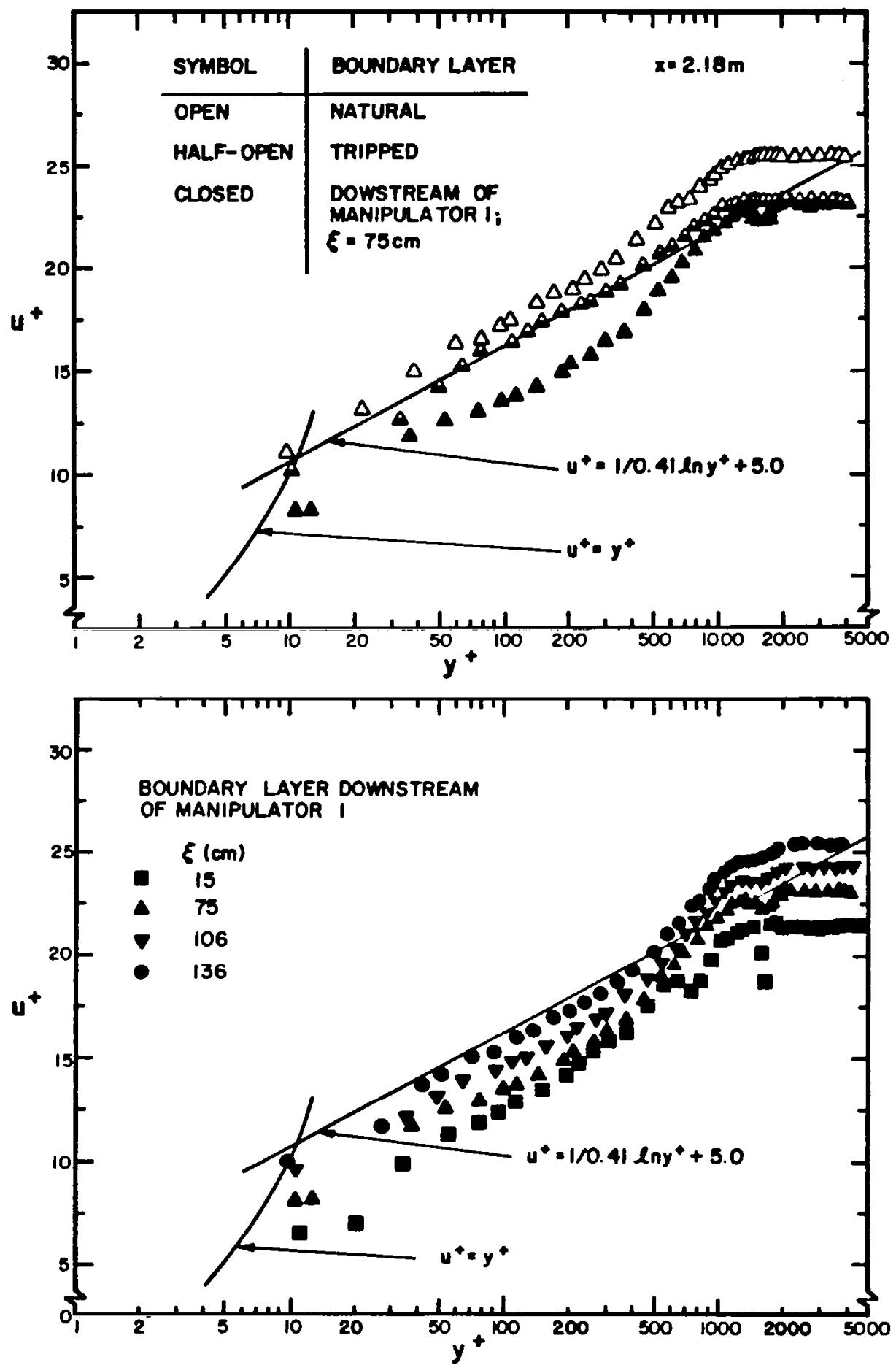

Figure 6. Log-linear representation of normalized velocity profiles for 3 boundary layer cases at one streamwise station (top), and for manipulated boundary layer at different stations; $U_{\tau}$ computed from momentum equation. 


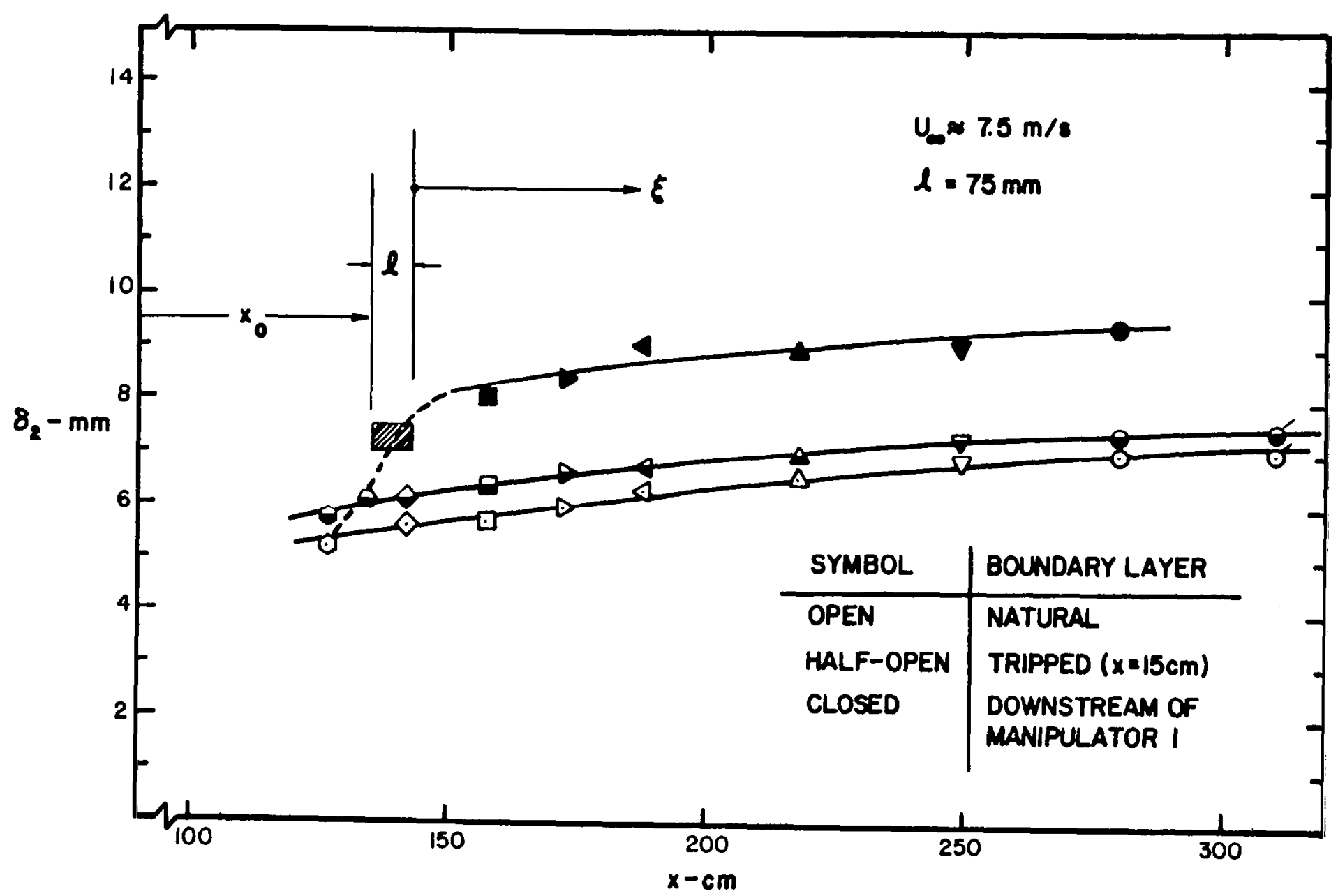

Figure 7. Downstream development of momentum thickness for natural, tripped and manipulated boundary layers 

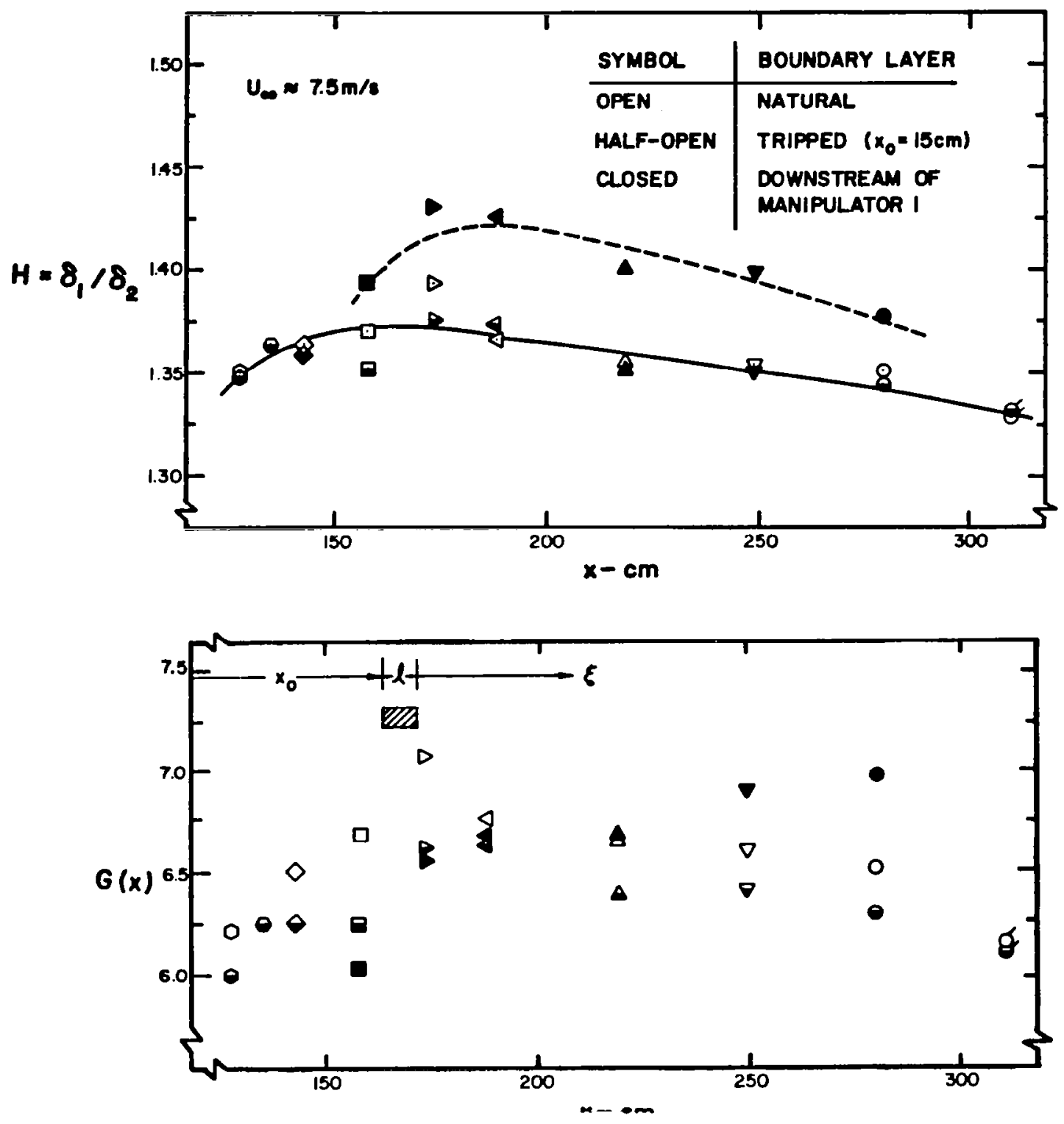


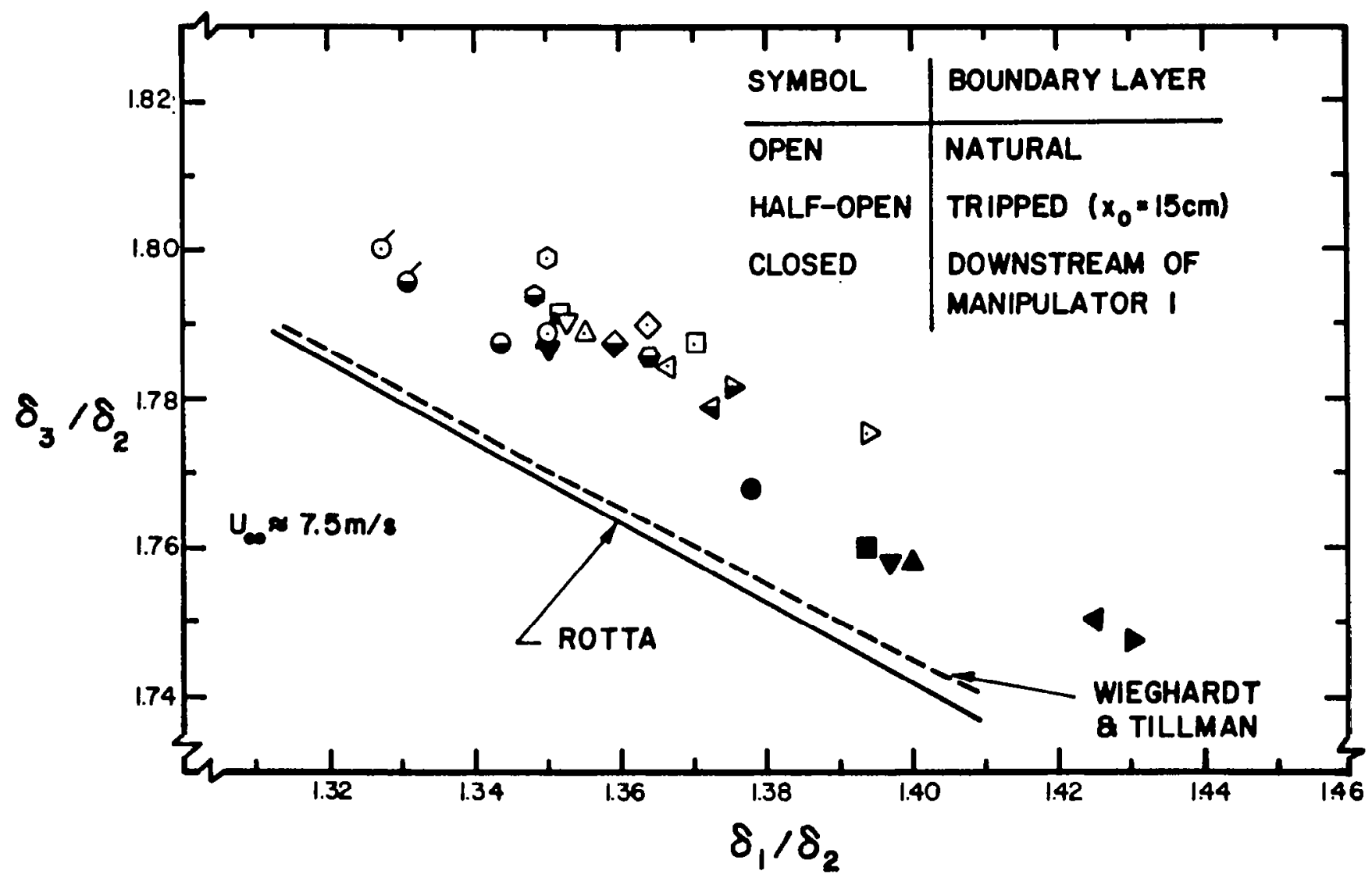

Figure 9. Correlation of energy to momentum thickness ratio with shape factor for natural, tripped and manipulated boundary layers. 


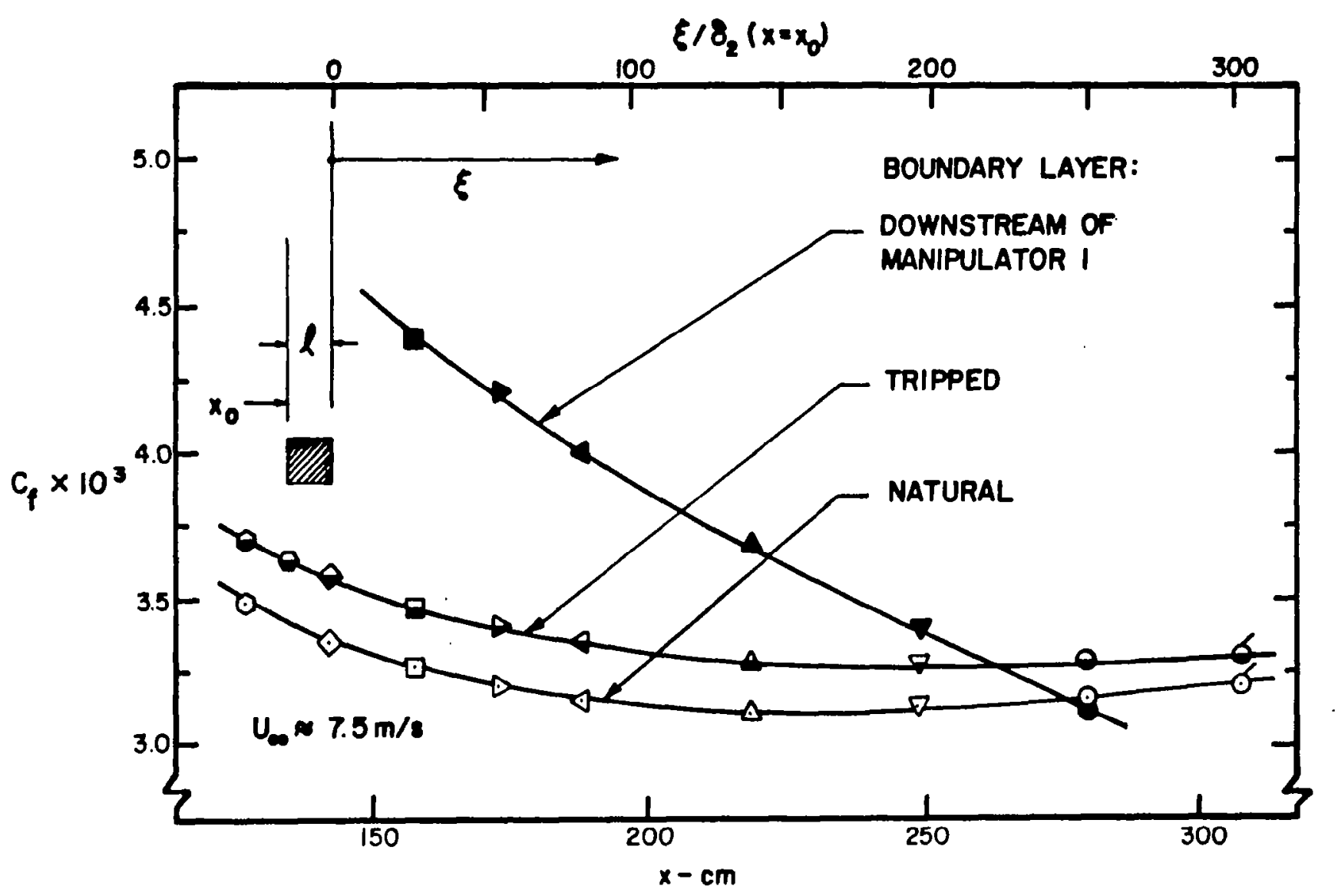

Figure 10. Downstream variation of friction coefficient for natural, tripped and manipulated boundary layers; $U_{\tau}$ computed from momentum equation. 


\begin{tabular}{|c|c|c|}
\hline & \begin{tabular}{l|l} 
Report No. & 2. Governn \\
NASA CR-3444 & \\
\end{tabular} & 3. Recipient's Catalog No. \\
\hline \multirow{2}{*}{\multicolumn{2}{|c|}{$\begin{array}{l}\text { 4. Title and Subtitle } \\
\text { MODIFICATION IN DRAG OF TURBULENT BOUNDARY LAYERS } \\
\text { RESULTING FROM MANIPULATION OF LARGE-SCALE STRUCTURES }\end{array}$}} & $\begin{array}{l}\text { 5. Report Date } \\
\text { JuTy } 1981\end{array}$ \\
\hline & & 6. Performing Organization Code \\
\hline \multicolumn{2}{|r|}{$\begin{array}{l}\text { 7. Author(s) } \\
\text { T. C. Corke, Y. Guezennec, and H. M. Nagib }\end{array}$} & 8. Performing Organization Report No. \\
\hline \multicolumn{2}{|r|}{ 9. Performing Organization Name and Address } & 10. Work Unit No. \\
\hline \multicolumn{2}{|r|}{$\begin{array}{l}\text { Illinois Institute of Technology } \\
\text { MMAE Department } \\
\text { Chicago, Illinois } 60616\end{array}$} & $\begin{array}{l}\text { 11. Contract or Grant No. } \\
\text { NSG- } 1591\end{array}$ \\
\hline & Sponsoring Agency Name and Address & $\begin{array}{l}\text { 13. Type of Report and Period Covered } \\
\text { Contractor Report }\end{array}$ \\
\hline & $\begin{array}{l}\text { National Aeronautics and Space Administration } \\
\text { Washington, DC } 20546\end{array}$ & 14. Sponsoring Agency Code \\
\hline \multicolumn{3}{|c|}{$\begin{array}{l}\text { 15. Supplementary Notes } \\
\text { Langley Technical Monitor: Jerry N. Hefner } \\
\text { Interim Report }\end{array}$} \\
\hline \multicolumn{3}{|c|}{ 16. Abstract } \\
\hline & \multicolumn{2}{|c|}{$\begin{array}{l}\text { The effects of placing a parallel-plate "turbulence manipulator" in a boundary } \\
\text { layer were documented both through flow visualization, using a "smoke-wire", and } \\
\text { hct-wire measurements. The boundary layer manipulator was designed to manage } \\
\text { the large-scale structures of turbulence in a way that may lead to a reduction } \\
\text { in the surface drag. First, the outcome of the visualization study is presented } \\
\text { to highlight the differences in the turbulent structure of the boundary layer } \\
\text { with and without the introduction of the manipulator. Secondly, hot-wire data } \\
\text { are summarized to demonstrate differences in various flow properties such as, } \\
\text { mean velocity and turbulence intensity profiles, displacement, momentum and } \\
\text { energy thicknesses, as well as various ratios of these, and the local friction } \\
\text { coefficient along the plate. The parallel-plate manipulator used in this study } \\
\text { was found very effective in inhibiting the intermittent large-scale structure of } \\
\text { the turbulent boundary layer. This effect persists for at least } 70 \text { boundary } \\
\text { layer thicknesses downstream of the manipulator. With the removal of the } \\
\text { large scale, there was an observed reduction in the streamwise turbulence } \\
\text { intensity levels near the wall. The downstream distribution of the skin friction } \\
\text { coefficient, determined from the streamwise change in fluid momentum, was also } \\
\text { altered by the introduction of the manipulator. In particular, it decayed at a } \\
\text { greater rate than for the non-manipulated boundary layer, although up to the } \\
\text { man... }\end{array}$} \\
\hline
\end{tabular}

